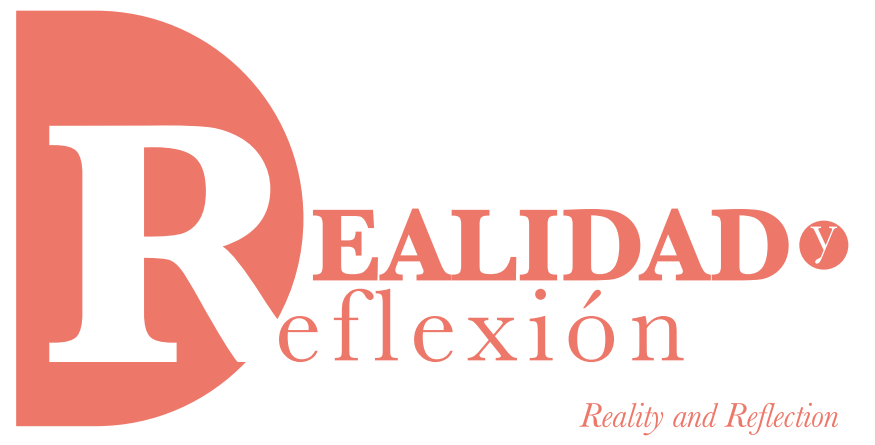

ISSN 1992-6510

e-ISSN 2520-9299

Año 19, N 49, San Salvador, El Salvador, Centroamérica. Revista Semestral Enero-Junio 2019

YEAR 19, N 49, SAN SALVADOR, EL SALVADOR, CENTRAL AMERICA. SEMESTRAL JOURNAL JANUARY-JuNE 2019

\title{
Venezuela en su poesía...siete caminos para fijar un rostro en la memoria
}

\author{
Venezuela in its poetry... seven ways to determinate \\ a face in the memory
}

(Ponencia presentada la XIV Jornada de Investigación Literaria que se celebró en la Universidad de Concepción - Chile)

Wilfredo Illas

Doctor en Educación de la Universidad de Carabobo, Venezuela. Doctorando en Literatura Latinoamericana, Universidad de Concepción, Chile illasw@hotmail.com

Fecha de recepción: 11 de abril de 2019 Fecha aprobación: 7 de junio de 2019 DOI: $10.5377 /$ ryr.v49i49.8065

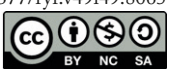

Mil emociones, a cual más intensa, le traían vibrando desde el alba: unas tristes, otras alegres, luchaban todas entre sí, pero sin alcanzar ninguna el predominio. Ídolos rotos. Manuel Díaz Rodríguez (1901)

\section{RESUMEN}

El artículo es un viaje en la memoria para exaltar el aporte de los poetas venezolanos fundacionales y contemporáneos para evitar el olvido y el desconocimiento de las raíces que explican a Venezuela como nación.

Palabras clave: poesía; poetas venezolanos; literatura; Venezuela.

\section{ABSTRACT}

The paper is a trip to the memory to exalte the foundational and contemporaries venezuelan poets' contribution to prevent forget unawaneress of roots that explain Venezuela as a nation.

Keywords: poetry; venezuelan poets; literature; Venezuela. 
Son esas mil emociones las que hoy me estrechan con las letras de mi país y con una tarea pendiente, en esta, la Universidad de Concepción, mi alma máter.

Para fijar un rostro (1984) ha sido considerada como la reflexión más amplia y profunda que se ha suscitado en torno a la narrativa venezolana, escrita por el profesor, poeta y amigo José Napoleón Oropeza, quien completa su estudio con otra obra del mismo valor, titulada El habla secreta (2002), en la cual ahora reflexiona sobre la poesía venezolana. De él entonces, tomo su aliento poético y esa necesidad de fijar un rostro que ahora no se complace solo en enumerar una lista de poetas para reflexionar en torno a su obra dentro de la literatura venezolana, sino que ahora emerge como necesidad de hacer un viaje en la memoria para participar de un eterno retorno obligatorio que nos permita por una parte, exaltar el aporte de nuestros poetas fundacionales y contemporáneos a lo que se erige como patrimonio literario nacional, evitando el olvido y con ello el desconocimiento de aquellas raíces que vienen a explicar lo que somos como nación; y, por la otra, reconocer algunas áreas desatendidas por la crítica especializada que puedan constituirse en terreno fértil de investigación y reflexión posibilitando el abono de inéditas rutas para comprender los nuevos rumbos de nuestra literatura.

\section{Primer camino}

Críticos, investigadores y estudiosos coinciden en que la obra de Andrés Bello (1781-1865) instaura la construcción de lo que denominamos literatura venezolana. $\mathrm{Su}$ permanente preocupación pedagógica, su convicción humanista y la exaltación en él de profundos ideales de libertad, igualdad y progreso, movilizaron en el escritor y en el hombre una conciencia profundamente política y cultural que le permitieron observar en la lengua una ocasión propicia y fundamental de integración; en la educación, un compromiso necesario para el progreso de nuestras nacientes repúblicas;y, en la poesía, la conjugación de estos nobles ideales en una escritura que más allá de invocación a los clásicos, imitación a la naturaleza, sentido universal o métrica uniforme, mostraba su apego y responsabilidad con los procesos civilizatorios de Hispanoamérica.
Divina poesía, tú, de la soledad habitadora, a consultar tus cantos enseñada con el silencio de la selva umbría; tú, a quien la verde gruta fue morada, y el eco de los montes compañía; tiempo es que dejes ya la culta Europa, que tu nativa rustiquez desama, y dirijas el vuelo adonde te abre el mundo de Colón su grande escena. También propicio allí respeta el cielo la simple verde rama.

Alocución a la Poesía. Andrés Bello (1823)

Lo que sigue no se queda en el encasillamiento neoclásico, en la intención didáctica de invitación a la musa o en el sentido universal de sus preocupaciones. Lo que sigue es más, es un canto que nos hermana ante una historia común, ante esa riqueza heredada que también es compartida y un compromiso humano que vio en la cultura el único germen posible para alcanzar un verdadero progreso que, ante todo, es de civilidad. 
Redundar en sus aportes, en la grandeza de su formación, en los infortunios y descalabros que debió vivir y en su significativa presencia para lo que sería la historia de nuestra naciente vida republicana, permite entender por una parte, la articulación de nuestros pueblos desde ese interés de integración cultural; y, por la otra, advertir con lucidez ese exilio permanente que lo ubicó en el centro de importantes episodios históricos, capaces de alimentar en él no solo su humanismo, sino su responsabilidad con las letras americanas. Hacer una mirada retrospectiva de su obra es encontrar los vínculos que mantiene con la tradición y con el devenir de nuestra literatura lo que nos habla de la innegable vigencia de su pensamiento.

\section{Segundo camino}

El romanticismo encuentra su esplendor en la obra del poeta José Antonio Maitín (1804-1874). Alrededor de tres búsquedas fundamentales: exaltación del yo, identificación de los estados de ánimo con la naturaleza y el empleo desbordado de interrogaciones y exclamaciones; el poeta nos brinda una obra en que la muerte es parte de un destino trágico irremediable capaz de suscitar el predominio de la melancolía como estado de ánimo propicio para penetrar en el intimismo del ser y desde esa esquina, dibujar con exacta dimensión las coordenadas del espacio inmediato. Su obra cumbre Canto fúnebre permite, además de examinar los rasgos emblemáticos del romanticismo literario, impulsar una elegía quejumbrosa desplazada en ese paisaje cotidiano que se ve sacudido por sus dolores, pasiones y preocupaciones:
¡Te fuiste sin saber que te sentía!

$¡$ Te fuiste sin saber que te lloraba!

No pude darte esta última alegría, y tú, ni este consuelo

¡le pudiste dejar al que te amaba!

Si yo quedaba aquí, ¿Por qué partiste?

¿Por qué ese amargo cáliz de infortunio

hacerme saborear con tal exceso?

¿Por qué morir del modo que moriste?

¿Por qué no recibir mi último beso?

¿Por qué dejarme en soledad tan triste?

¡Mi Dios!, ¡mi Dios!, ¿Cómo fue eso?

Canto Fúnebre. José Antonio Maitín (1851)

Exilio, muerte, soledad, ruina, historia espiritual y diario vivir son en conjunto los elementos con los que el poeta no solo construye un mundo de pesadumbre, desconsuelo e inquietante preocupación existencial; son además, las pistas con las que la obra progresivamente devela un sentir, una pena, un alma romántica... sobre todo un paisaje que es ante todo humano; en fin, un tránsito por esa comarca íntima en que se desnudan los sentidos para luchar con esas tinieblas que siempre envuelven la realidad humana.

Entender el valor agregado que este poeta hereda con su obra al romanticismo en la poesía venezolana, así como profundizar en esos paisajes poetizados que logra construir desde la inmediatez de las imágenes, son aún tareas pendientes de una crítica especializada que necesariamente deberá volver la mirada a su obra y escudriñar en ella esa nueva sensibilidad que se empeñó en enlazar la literatura con la vida en ese aliento poético intimista y confesional que resonará para siempre en nuestras letras. Otros románticos son importantes exponentes del movimiento 
en Venezuela, a saber: Juan Vicente González, Cecilio Acosta, Abigail Lozano y Fermín Toro.

\section{Tercer camino}

En la transición romanticismo - modernismo, destaca la figura de Juan Antonio Pérez Bonalde (1846-1892). Para algunos críticos es la máxima figura del romanticismo; sin embargo, otros destacan en su obra un amplio sentido visionario y adelantado que lo ubicaría en el surgimiento de la corriente modernista en Venezuela. Su tono melancólico obedece a largos períodos de exilio, a la frustración ante un proyecto de país que nunca pudo ver materializado por la agitación política, las permanentes guerras y el predominio del caudillismo; y, sobretodo, a diversos golpes dolorosos que le ocasionó la muerte sus afectos familiares.

En su poema Tienen razón, Bonalde nos muestra su férrea oposición contra la tiranía política, la dictadura y opresión militar y la miseria social, económica y cultural en la que estaba sumida su patria:

Oprimir a mi patria: esa es tu gloria

Egoísmo y codicia: ese es tu lema

Vergüenza y deshonor: esa es tu historia;

por eso, aún en su infortunio recio, ya el pueblo no te lanza su anatema... ¡Él te escupe a la cara su desprecio!

Tienen Razón. Juan Antonio Pérez Bonalde

Si bien el poeta tiene importantes obras como Poema al Niágara o Vuelta a la patria, es en esta última donde encontramos el clímax de su sentir melancólico ocasionado por el exilio y la muerte de su madre, todo ello acompañado de esa íntima relación vida y arte, el refugio de los estados del alma en la naturaleza y esa duda romántica que moviliza la interpelación de la existencia y sus destinos:

Madre, aquí estoy, de mi destierro vengo a darte con el alma el mudo abrazo que no te pude dar en tu agonía; a desahogar en tu glacial regazo la pena aguda que en el pecho tengo y a darte cuenta de la ausencia mía. $\cdots$

Triste, enfermo y sin calma, en ti pensaba yo cuando me dieron la noticia fatal que hirió mi alma, lo que sentí, decirlo no sabría... solo sé que mis lágrimas corrieron como corren ahora, madre mía.

Vuelta a la Patria. Juan Antonio Pérez Bonalde

Imposible dejar de mencionar en esta apretada síntesis el poema Flor, considerado como el máximo canto elegíaco de nuestra poesía. Bonalde dedica este delicado canto a su hija muerta, en el cual no solo muestra cómo su alma se desgarra de dolor en esa búsqueda de exaltación del yo, sino que además la duda romántica deja en evidencia su preocupación por el incierto de la existencia y en arrebato de desespero y profunda tristeza, interpela también con vacilación, la existencia de Dios. Exclamaciones e interrogaciones vienen a profundizar el retrato de esos estados de ánimo que el poeta revela con vehemencia: 
¡Señor! ¿Existes? ¿Es cierto que eres consuelo y premio de los que gimen, que en tu justicia tan solo hieres al seno impuro y al torvo crimen?

Responde, entonces: ¿por qué la heriste? ¿Cuál fue la mancha de su inocencia? ¿Cuál fue la culpa de su alma triste? ¡Señor!, respóndeme en la conciencia

Y en torno sigue la impía calma de este misterio que llaman vida, y en tierra yace la flor de mi alma ¡y al lado suyo mi fe vencida!

\section{Flor. Juan Antonio Pérez Bonalde (1883)}

Estamos frente a un poeta de obligatoria referencia en el devenir de las letras venezolanas, quien conjugó en su obra esa profunda exaltación del yo con una delicada evasión lograda por la exploración de realidades sensoriales que dejaban al descubierto un dolor descarnado, todo ello enmarcado en la musicalidad y en el empleo del juego simbólico; así, la patria es Venezuela, pero también la madre y Flor es la hija pero también la pureza y la esperanza arrebatada. Una de sus estrategias recurrentes es la transfiguración de la imagen poética en el devenir del poema a través de la ironía, sobretodo en cuanto a las entidades: mal, Dios o justicia, veamos:

En el tiempo, en el espacio, en la materia infinita, donde la vida se agita en la eterna evolución, allí palpita, se mueve Dios.
En la vida, en la materia, donde quiera el mal se esconde, y donde quiera responde al grito del corazón...

Decidme, ¿̇ónde, dónde está Dios?

\section{¿Dónde está Dios? Juan Antonio Pérez Bonalde}

En el olvido ha ido quedando el estudio de su obra y la reflexión en torno a lo que sería su propuesta estética, la cual no solo constituyó una forma de vida, sino que marcó nuevos rumbos en la poesía venezolana. Volver a Pérez Bonalde, o a Manuel Fombona Palacios, Jacinto Gutiérrez Coll, Andrés Mata, entre otros; no sería repasar la presencia del exilio, el predominio del yo o la melancolía manifiesta; sería además, adentrarnos en el compromiso social de esta escritura, en el reflejo de una condición humana que trascendió las fronteras de su propia existencia y en esas construcciones estéticas que auguraban ruptura, nuevas rutas de exploración temática e inéditas formas de composición. Mirar las obras fundacionales desde otro lugar repleto de partidas, preguntas y emociones; es, además de experimentar nuevos significados y sensibilidades, plantearse distintas formas para apropiarse del texto y expresar sus sentidos. Por ejemplo, leer en la distancia el exilio desde la condición de exiliado, implica no solo vibrar al mismo impulso del poema y su creador, sino interpretar, comprender y recrear el texto desde una perspectiva crítica y reflexiva articuladas por la amplitud del pensamiento y el enriquecimiento del espíritu.

Cuarto camino 
El modernismo en Venezuela se encontró en una coyuntura socio histórica y cultural que lo ubicó en una encrucijada de doble vertiente: por una parte estuvo la evasión, el exotismo y cosmopolitismo; por la otra, el criollismo, el valor de lo autóctono y el reconocimiento artístico del terruño. Dictaduras y convulsiones sociales contextualizaron su surgimiento y desarrollo en el país, por esta razón nos encontramos con un Alberto Soria de Ídolos rotos que vuelve al país y se frustra al encontrarlo sumido en un profundo atraso económico y cultural, razón que le hace anhelar su vida parisina y evadir su pensamiento permanentemente hacia esas latitudes; en contraparte, la Silva Criolla de Francisco Lazo Martí (1869-1909) invita a ese bardo amigo a que retorne a su pueblo, a que se refugie en el espectáculo natural que encierra el llano y a que disfrute el calor humano de sus raíces. Este poema es considerado un canto de alegría ante el valor del arraigo, ante la riqueza del campo venezolano; en fin, ante la necesidad de volver a los orígenes para celebrar las cosas sencillas de la vida y reivindicar el valor de lo propio:

Es tiempo de que vuelvas; es tiempo de que tornes...

No más de insano amor en festines, con mirto y rosa y pálidos jazmines tu pecho varonil, tu pecho exornes. Es tiempo de que vuelvas... Tu alma -pobre alondra- se desvive por el beso de amor de aquella lumbre deleite de sus alas. Desde lejos la nostalgia te acecha. Tu camino se borrará de súbito en su sombra... Y voz doliente de las horas tristes, $\mathrm{y}$ del mal vivir oculto dardo, el recuerdo que arraiga y nunca muere, el recuerdo que hiere, hará sangrar tu corazón, ¡Oh Bardo! $\ldots$

Por amor a tu raza en desventura; por esta pobre tierra, que el maléfico genio de la guerra convierte ya en enorme sepultura; por estos seres buenos y sencillos; por este pueblo amado, que vive - noble víctima - entregado a la ciega ambición de los caudillos .

Tus pasos vuelve hacia el hogar, joh bardo! yace por tierra el matizado velo con el cual primavera engalanaba los montes de tu suelo.

\section{Silva Criolla. Francisco Lazo Martí (1901)}

Su escritura está vinculada a tres preocupaciones fundamentales: reflexión permanente en torno a la existencia, el tema del llano venezolano y el empeño en crear un campo alegórico que explora lo sensorial para encontrar en la musicalidad un fluir nacionalista, el cual le permitió describir el paisaje natural trascendiéndolo a través de la fusión con el plano psicológico.

La crítica literaria ha visto en Lazo Martí a ese poeta criollista que con su obra intentó reivindicar el valor de lo autóctono y el retrato de la fisonomía del pueblo; sin embargo, hay en su escritura más que eso, está toda una corriente artística que instaura modos distintos de crear y moralizar, nuevos conceptos de nacionalismo, e incluso, el establecimiento de puntos de convergencia en los cuales confluye y logra convivir toda la tradición literaria anterior. 
Esa poesía del llano, de lo autóctono, de la vida sencilla del campesino, que podemos también encontrar en grandes poetas venezolanos como Alberto Arvelo Torrealba, Alfredo Arvelo Larriva, José Arreaza Calatrava o el mismo Cruz Salmerón Acosta, debe constituirse en un ámbito vigente de estudio y reflexión, pues a la combinación de elementos neoclásicos, románticos y modernistas, se le suma la vuelta a los orígenes, el ejercicio de una sensibilidad consustanciada con los ideales de paz, justicia y arraigo; y el reconocimiento de un paisaje natural que se funde con el paisaje humano para reflexionar en torno a la existencia, salvar el compromiso social y escudriñar en los estados profundos de la consciencia.

\section{Quinto camino}

Convulsa sigue la vida nacional y en los intersticios de aliento ideológico y desarrollo cultural, se gesta la transición entre modernismo y vanguardismos. En esa rendija se ubica la obra de Andrés Eloy Blanco (1896-1955). Considerado por historiadores, críticos de arte e investigadores culturales como el poeta del pueblo. Representa un peldaño importante de lo que ha sido la construcción de nuestra literatura venezolana, pues elevó las búsquedas de lo autóctono hacia las tensiones propias de la angustia existencial y la incertidumbre, lejos de preferir el hermetismo dejó que su creación fluyera mediante una escritura vibrante que vendría a instalarse para siempre en la fibra más sensible de su gente, en ese apostolado de compromiso social, de amor descarnado y de interés moralizante. Conocidos son sus versos:

Pintor de santos de alcoba, pintor sin tierra en el pecho, que cuando pintas tus santos no te acuerdas de tu pueblo, que cuando pintas tus Vírgenes pintas angelitos bellos, pero nunca te acordaste de pintar un ángel negro.

Pintor nacido en mi tierra, con el pincel extranjero, pintor que sigues el rumbo de tantos pintores viejos, aunque la Virgen sea blanca, píntame angelitos negros.

Pintame angelitos negros. Andrés Eloy Blanco

El exilio, la participación política, el desgarro ante la ausencia y los avatares de una vida golpeada por los infortunios de las circunstancias encontraron un lugar en su obra que a ratos era un canto genuino de ese intimismo confesional y a ratos era el canto de todo un país que encuentra en sus versos el reflejo más auténtico de su sentir.

Madre: esta noche se nos muere un año.

En esta ciudad grande, todos están de fiesta; zambombas, serenatas, gritos, ¡ah, cómo gritan!;

claro, como todos tienen su madre cerca...

¡Yo estoy tan solo, madre,

tan solo!; pero miento, que ojalá lo estuviera; estoy con tu recuerdo, y el recuerdo es un año pasado que se queda.

$\ldots$

Madre, esta noche se nos muere un año; todos estos señores tienen su madre cerca, y al lado mío mi tristeza muda tiene el dolor de una muchacha muerta... $\mathrm{Y}$ vino toda la acidez del mundo 
a destilar sus doce gotas trémulas, cuando cayeron sobre mi silencio las doce uvas de la Noche Vieja.

Las uvas del tiempo. Andrés Eloy Blanco (1934)

Su pueblo entero forma parte de esos hijos infinitos. Su legado literario se mezcló con la cotidianidad de un país que se reconoce en su pluma...que se encuentra en las calles de sus creaciones:

Cuando se tiene un hijo, se tiene al hijo de la casa y al de la calle entera, se tiene al que cabalga en el cuadril de la mendiga

y al del coche que empuja la institutriz inglesa y al niño gringo que carga la criolla

y al niño blanco que carga la negra

y al niño indio que carga la india

y al niño negro que carga la tierra.

Cuando se tiene un hijo, se tienen tantos niños

que la calle se llena

y la plaza y el puente

y el mercado y la iglesia

y es nuestro cualquier niño cuando cruza la calle

y el coche lo atropella

y cuando se asoma al balcón

y cuando se arrima a la alberca;

y cuando un niño grita, no sabemos

si lo nuestro es el grito o es el niño,

y si le sangran y se queja,

por el momento no sabríamos

si el ¡ay! es suyo o si la sangre es nuestra.

Cuando se tiene un hijo, es nuestro el niño que acompaña a la ciega

y las Meninas y la misma enana

y el Príncipe de Francia y su Princesa

y el que tiene San Antonio en los brazos

y el que tiene la Coromoto en las piernas.

Cuando se tiene un hijo, toda risa nos cala, todo llanto nos crispa, venga de donde venga. Cuando se tiene un hijo, se tiene el mundo adentro

y el corazón afuera.

Los hijos infinitos. Andrés Eloy Blanco (1955)

Si bien es cierto que la crítica especializada no ha desatendido su obra, nos queda aún seguir leyendo sus creaciones y su herencia para leer en ellas al país y encontrar en sus paisajes su esencia cultural; pero, sobre todo, para reconocer en su estilo fresco y contestatario, los vínculos de una estética que no solo logra convivir con la vanguardia sino fundirse en todos los marcos artísticos e ideológicos que han ido germinando y, por ende, definiendo el devenir de la literatura contemporánea venezolana. Su escritura representó un quiebre no solo temático y literario, también lo fue ideológico y cultural. Aún hoy nos cuesta entender las complejidades de esa aparente sencillez, la emergencia de nuevas formas que movilizan una ruptura con la tradición y la fascinación con la que su obra, sin formar parte de cánones académicos u oficiales, ha logrado calar en la gente, en la cultura, en la historia y en ese lugar de referencia obligatoria para todo aquél que intente comprender el panorama actual de la poesía venezolana.

Pertenecen además, a este trasiego de transiciones, búsquedas y rupturas, escritores de la talla del conocido Antonio Ramos Sucre, Fernando 
Paz Castillo, Enrique Planchart, Luis Enrique Mármol, Héctor Cuenca, Humberto Tejera, Pío Tamayo, solo por mencionar algunos poetas que se ubicarían en este escenario temporal.

\section{Sexto camino}

Corren los tiempos y llega la vanguardia. Muchos escritores pasan ese umbral para arribar a una estética que celebra la ruptura con todas las formas y cánones anteriores, la expresión hermética, la libertad temática, el espíritu subversivo y ese aliento ideológico que transcendió lo estético para constituirse en signo de lo que ocurría en el plano social, político, cultural e histórico. Muchos estudios han explicado la emergencia y desarrollo de la vanguardia venezolana. Válvula, Grupo Viernes o Tabla redonda son manifestaciones culturales de referencia obligatoria para entender la construcción de una estética que adquirió los matices que le fueron imprimiendo la actitud de cambio, el desencanto y el ímpetu revolucionario experimentados en el plano social y político. Nuevos lenguajes, nuevos valores y nuevas preocupaciones fue el caldo de cultivo para pensar la inconformidad que suscitaba el mundo contemporáneo. Vicente Gerbasi (19131992) fue nuestra máxima figura de la poesía vanguardista venezolana. Su obra cumbre, $M i$ padre el inmigrante, recoge la inquietud de toda una generación, se erige alrededor de un conjunto de características que no son solo literarias, también son epocales; en fin, expresa la inquietud más fehaciente de un terreno existencial en el cual no quedan certezas, tampoco proyectos:

Venimos de la noche y hacia la noche vamos. Atrás queda la tierra envuelta en sus vapores, donde vive el almendro, el niño y el leopardo.
Atrás quedan los días, con lagos, nieves, renos,

con volcanes adustos, con selvas hechizadas donde moran las sombras azules del espanto. Atrás quedan las tumbas al pie de los cipreses, solos en la tristeza de lejanas estrellas.

Atrás quedan las glorias como antorchas que apagan

ráfagas seculares.

Atrás quedan las puertas quejándose en el viento.

Atrás queda la angustia con espejos celestes.

Atrás el tiempo queda como drama en el hombre:

engendrador de vida, engendrador de muerte. El tiempo que levanta y desgasta columnas, y murmura en las olas milenarias del mar.

\section{Mi padre el inmigrante. Vicente Gerbasi (1986)}

La vanguardia literaria tuvo un importante grupo de adeptos y la mayor demostración de ello ha sido la cantidad de escritores que contagiaron su obra con este aliento estético. Particularmente la obra de Gerbasi continúa en el centro de la crítica literaria, pues en el devenir de nuestras letras, se ha entendido que este autor tiene aún mucho que enseñarnos y, por ende, su propuesta escritural tiene mucho aún por descubrir. Solo restaría reflexionar qué vínculos continúa estableciendo la obra de Gerbasi con las nuevas voces que van germinando el terreno fértil de la literatura venezolana o cómo se vehiculan desde nuevos lugares de producción la configuración de temas recurrentes que vienen a reinventarse con esta emergencia estética. Afortunadamente, la figura de Gerbasi no eclipsó a los escritores de su generación ni de las siguientes generaciones, por el contrario, les permitió un espacio para 
asumir una propia voz, para ejercitar sus propias búsquedas y para alimentar desde sus genuinas inquietudes lo que fue la vanguardia dando cabida a su vez, al surgimiento de inéditos proyectos escriturales. En el caso de nuestra poesía escrita por mujeres, resulta válido este espacio para reconocer el valor de la obra de Enriqueta Arvelo Larriva.

Este sexto camino forma parte de una encrucijada en que se van tejiendo múltiples rutas. Solo por mencionar, tenemos la obra de Rafael Cadenas (1930) o la de Gustavo Pereira (1941) escritores que se corresponden a generaciones anteriores de mediados de siglo XX pero que su aporte convive con la propuesta de nuevos artistas que siguen germinando alrededor de la convulsión política, la lucha reivindicatoria y el exilio. De Cadenas heredamos esas exactitudes aterradoras:

Que cada palabra lleve lo que dice.

Que sea como el temblor que la sostiene.

Que se mantenga como un latido.

No he de proferir adornada falsedad ni poner tinta dudosa ni añadir brillos a lo que es.

Esto me obliga a oírme. Pero estamos aquí para decir verdad.

Seamos reales.

Quiero exactitudes aterradoras.

Tiemblo cuando creo que me falsifico. Debo llevar en peso mis

palabras. Me poseen tanto como yo a ellas.

Ars poética. Rafael Cadenas (1991)

Pero también esa derrota que se cuela en nuestra fibra para robarnos por momentos esa sonrisa que nos caracteriza y hacernos pensar entonces en ese fracaso existencial que sigue latente en la incertidumbre que controla los hilos del destino humano:

Yo que no he tenido nunca un oficio que ante todo competidor me he sentido débil

que perdí los mejores títulos para la vida que apenas llego a un sitio y ya quiero irme (creyendo que mudarme es una solución) que he sido negado anticipadamente $y$ escarnecido por los más aptos que me arrimo a las paredes para no caer del todo

que soy objeto de risa para mí mismo que creí que mi padre era eterno que he sido humillado por profesores de literatura

que un día pregunté en qué podía ayudar y la respuesta fue una risotada

que no podré nunca formar un hogar, ni ser brillante, ni triunfar en la vida

que he sido abandonado por muchas personas porque casi no hablo

que tengo vergüenza por actos que no he cometido

que poco me ha faltado para echar a correr por la calle

que he perdido un centro que nunca tuve que me he vuelto el hazmerreír de mucha gente por vivir en el limbo que no encontraré nunca quién me soporte...

Derrota. Rafael Cadenas (1970)

De Pereira nos asombra su lucha incansable por nuestra herencia ancestral, su permanente arrojo hacia la denuncia social y la lucidez con los que ha advertido nuestros desatinos históricos $\mathrm{y}$ 
culturales. Su permanente burla e interpelación queda retratada en esta producción suya:

Los pemones de la Gran Sabana

llaman al rocío Chirike-yeetakuú que significa Saliva de las Estrellas;

A las lágrimas Enú-parupué que quiere decir Guarapo de los Ojos, y al corazón Yewán-enapué:

Semilla del Vientre.

Los waraos del Delta del Orinoco dicen Mejokoji

(El Sol del Pecho) para nombrar el Alma.

Para decir amigo dicen Ma-jokaraisa: Mi otro corazón.

Y para decir olvidar, dicen: Emonikitane, que quiere decir Perdonar.

Los muy tontos no saben lo que dicen:

Para decir Tierra dicen Madre

Para decir Madre dicen Ternura

Para decir Ternura dicen Entrega

Tienen tal confusión de sentimientos que con toda razón

las buenas gentes que somos

les llamamos salvajes.

Sobre salvajes. Gustavo Pereira (2007)

Es válido destacar que este camino está signado por la presencia de los grupos literarios. Por ejemplo Rafael Cadenas perteneció a Tabla Redonda junto a poetas como Jesús Sanoja Hernández o José Berroeta. Otros grupos fundamentales serían Sardio y el Techo de la Ballena en cuyas propuestas se inscribirían las obras de los poetas Ramón Palomares,
Caupolicán Ovalles, Francisco Pérez Perdomo, Juan Calzadilla o Carlos Contramaestre. Tráfico con Armando Rojas Guardia, Miguel Márquez, Rafael Castillo Zapata, Yolanda Pantín, Igor Barreto, Alberto Márquez, entre otros; o, Guaire con Rafael Arraiz Lucca, Luis Pérez Oramas, Nelson Rivera, Armando Coll, Leonardo Padrón o Alberto Barreras Tyszka son también grupos literarios de referencia obligatoria en la poesía de fines del siglo XX. Consignas, manifiestos, trasgresiones, nuevos lenguajes, crisis, emergencia de la urbe, reacción política o desencanto social son la expresión y los puntos coincidentes de estos grupos que se erigen desde una ruptura estética, la cual encuentra cabida en un devenir histórico convulso, cargado de protestas y de ideales que luchan en un contexto sin proyecto, de crisis profunda y complejas tensiones socio históricas, políticas y económicas.

Otros nombres vienen al encuentro de un siglo que está por morir y de otro que intenta nacer al abrigo de lo inconcluso, el extravío y el quiebre. Es precisamente este contexto precario, repleto de desconcierto y desencanto el que se convierte en terreno fértil para una abundante producción poética caracterizada por genuinas propuestas estéticas, riqueza temática y exquisita construcción de imágenes con un lenguaje cargado de cotidianidad, de calle, juego, cuerpo, sudor y agitación circundante. Esos nombres, pertenecientes a las postrimerías del siglo $\mathrm{XX}$, serían, entre otros que se omiten por razones de extensión, el de Eugenio Montejo, Ana Enriqueta Terán, Ludovico Silva, Juan Liscano, Teófilo Tortolero, Alfredo Silva Estrada, Miyó Vestrini, Lydda Franco Farías, Alejandro Oliveros, Reinaldo Pérez So, Ida Gramcko, Juan 
Sánchez Peláez, Victor Valera Mora, Hanni Ossott o el de Luis Alberto Crespo.

\section{Séptimo Camino}

Este es el camino que nos lleva a un posible punto de llegada; es decir, al terreno de las (In) conclusiones:

\section{Posibles ámbitos problematizadores}

a. Es necesario volver la mirada, el estudio y la reflexión hacia estos escritores y otros tantos, cuyo aporte y propuesta estética siguen pendientes por descubrir. Leer en la distancia la obra de nuestros escritores fundacionales es alcanzar la única posibilidad válida para entender los rumbos y desafíos que explican el devenir de nuestra literatura venezolana.

b. Estos nombres son solo referencias obligatorias de una lista más amplia compuesta por hombres y mujeres que con su pluma enriquecieron y continúan cultivando el terreno fértil de la poesía venezolana. Con ellos también la crítica especializada está en deuda.

c. Se observa en todos nuestros escritores y en buena parte de poetas venezolanos, la constante de cinco vertientes temáticas: exilio, intimismo melancólico, angustia existencial, intención moralizante, poética contemplativa y militancia social; todo ello visto en un amplio horizonte político y cultural que viene a estrechar dos entidades en correspondencia: patria y poesía. Estas temáticas más que cegarnos ante encasillamientos innecesarios, deben propiciar la reflexión ante el encuentro con otras literaturas, la relación de circunstancias socio históricas y culturales que contextualizan la creación; y, con ese retorno necesario, continuar leyendo y explorando la obra de nuestros escritores venezolanos a fin de fijar un rostro en la memoria y así mirar desde diversas perspectivas el amplio mapa de la literatura venezolana dentro de un tapiz mayor representado por la literatura latinoamericana.

d. Otras posibilidades investigativas aún pendientes por explorar desde nuevos lugares de lectura serían: a) poesía venezolana escrita por mujeres, b) aquella que se ha escrito y se continúa escribiendo en el interior del país, que no tiene interés de pertenecer al centro, que se sigue produciendo en la periferia o que ha sido invisibilizada por el canon oficial, ésa de nuestros pueblos, de nuestras comunidades y regiones; c) la escrita en esta última década, una poesía deslocalizada, expresión de nuevos exilios y geografías, inéditas propuestas estéticas o testimonio de unos desplazamientos ideológicos que hablan de la emergencia de nuevas inquietudes, búsquedas y sensibilidades; $\mathrm{y}$ d) aquella poesía que nos puede dar cuenta de circunstancias humanas, históricas y contextuales que vista en perspectiva comparativa, podría hablarnos de otras latitudes, transiciones sociales, influjo, intercambio y reciprocidades.

\section{Posibles ámbitos epistémicos}

Si bien es cierto que, desde nuevas perspectivas, deben advertirse los rasgos y devenires del tejido cultural, y dentro de este, del fenómeno literario en Venezuela, es perentorio hacerlo - tal como afirma Virilio (1980)- a partir de una "estética de la desaparición”; es decir, de una racionalidad 
sustentada en la debilidad o derrumbe de unos discursos legitimantes y homogeneizantes, en el predominio del fragmento y en lo complejo que caracteriza la realidad circundante. En esta suerte, una revisión profunda y actual de nuestra literatura pasada y presente, debe moverse alrededor de las coordenadas de una era del vacío, tal como afirma García (2000), una dinámica temporo-espacial caracterizada por la deslocalización, atomización, inestabilidad e incertidumbre. Esta orientación ideológica exige necesariamente una mirada transdisciplinaria de la investigación literaria, una mirada que trascienda esquemas paradigmáticos, postule la cooperación disciplinar y articule esas especificidades del saber cómo un solo cuerpo que, pensado en conjunto, nos dé cuenta de la interacción de todos los factores que confluyen en la comprensión del hombre y su realidad. Precisamente, es este dialogismo el que permite a la literatura:

“...descubrir la complejidad del individuo escamoteada por la mirada cosificada y simplista de las disciplinas que lo estudian restringido a sus explicaciones y determinismos. La literatura no solo nos muestra el destino incierto de los hombres, sino también ahonda en sus deseos, en sus azares, sus locuras, sus pasiones, sus imaginarios, sus odios propios...La literatura, en su manera particular de pensar el mundo, nos confiere un aprendizaje tan agudo como el de los expertos, pero no basados en teorías, sino en la experiencia humana, y además, ella está henchida de ideas, verdades y esperanzas de los hombres", (pp. 24-27)

De esta forma, sobrevivir al abismo gracias a esa natural transdisicplinariedad que constituye inextricablemente al hecho literario, pues como dice Mathis (1999) "una sola obra literaria contiene un infinito cultural que engloba la ciencia, la historia, la religión, la ética...” (p. 53), es que se da apertura a múltiples perspectivas para comprender y reflexionar en torno a la experiencia humana que palpita en cada texto literario. En este sentido, nos dice García (ob. cit) que "la literatura reconoce la exigencia de una pluralidad de aproximaciones... Siendo transdisciplinaria [...] sus textos nos muestran la fragilidad de la racionalidad y la conexión dialógica de la afectividad, la pulsión y la racionalidad misma [...]" (p.31).

Aunado a ello, la Neohermenéutica podría articularse con la mirada transdisciplinaria y en conjunto saldar esa deuda de actualización y renovación que tiene pendiente la crítica especializada, cuya deuda se expresa en el desgaste cultural e intelectual de una tradición moderna (reduccionista, esquemática e invisibilizadora) que en este momento sería incapaz de generar nuevas miradas, asumir con pertinencia el devenir del arte y la literatura y plantear cuestionamientos generadores de perspectivas amplias para redimensionar no solo las formas que centralizan la crítica literaria, sino los resultados que de ellas han derivado. Para Prado (2009)

...la neohermenéutica (...) se refiere a un registro filosófico basado en el ejercicio de la interpretación de textos... en la reflexión, la comprensión (apropiación de sentido) y la autorreflexión... ahí precisamente es donde reside su riqueza: es preciso realizar una interpretación, una reflexión y llegar a la comprensión, siempre provisional, sobre 
la esencia y naturaleza del hecho literario... a la cual seguirá una autorreflexión por parte del sujeto que comprenda... a la vez que su autocomprensión y la ampliación de su horizonte comprensivo serán cada vez mayores... (pp.23-24).

Definitivamente la crítica especializada tiene que hacerse cargo de un mapa que destiñó sus fronteras y coordenadas, de una poesía que, al igual que el país, se encuentra extraviada; necesario es retomar esa búsqueda, reencontrarnos con el valor, el aporte y la trascendencia de esa poesía venezolana de ayer, de hoy, de siempre. Obviamente hay que construir un nuevo mapa, sin linealidades ni encasillamientos, sin consagraciones ni marginación... un mapa de esa fisonomía que nos define como pueblo, de esa geografía humana que brota de nuestra riqueza cultural, del torrente patrimonial que une a nuestros pueblos y que nos hace, en esencia, un solo cuerpo que vibra ante las tinieblas que de vez en vez vienen a recordarnos el sentir libertario, el determinismo y el encuentro de esa patria buena, hospitalaria, optimista y fraterna.

\section{Referencias}

García, A. (2000). La transdisicplinariedad. En II Encuentro por una lectura transdisciplinaria del texto literario (Ed). Valencia - Venezuela: Universidad de Carabobo

Mathis, G. (1999). La complexité au coeur de l'enseignement des lettres. En Morín, E. La cabeza bien puesta. París: Ed. Seuil.

Prado, G. (2009). Neohermenéutica y teoría literaria.En Prado,G y Téllez, A. Neohermenéutica literatura, flosofía y otras disciplinas. México: Ed. Universidad Iberoamericana.

Virilo, P. (1980). Esthétique de la disparition. París: Ed. Balland. 